\title{
23 Responsible supervisory authority
}

Data subjects have the right to lodge a complaint with the responsible supervisory authority. This should be specified precisely in the consent. In the case of an EU-wide project: which authority is the responsible supervisory authority in this case?

The requirement to indicate the competent authority in a consent form does not exist according to the GDPR. Merely in Article 13, 14 GDPR it is demanded (as part of the duty to inform), that the controller has to inform about "the right to lodge a complaint with a supervisory authority" (Article 13 para. 2d) GDPR; Article 14 para. 2e) GDPR). It is nowhere to be found in the law, that the competent authority has to be specified. ${ }^{76}$

However, the competent authority will usually be the state data protection commissioner of the federal state in which the controller is located. 